\title{
PERCEPÇÃO SOBRE O USO DE MADEIRA REFLORESTADA NOS MÓVEIS PELOS CONSUMIDORES DO POLO DE UBÁ (MG)
}

\author{
Ricardo Ribeiro Alves ${ }^{1}$, Laércio Antônio Gonçalves Jacovine², Fabrícia de Souza Cyrillo ${ }^{3}$, \\ Vanessa Aparecida Vieira Pires ${ }^{4}$, Andréia Aparecida Albino ${ }^{5}$ \\ ${ }^{1}$ Administrador, Dr., Depto. de Engenharia Florestal, UFV, Viçosa, MG, Brasil - ricardo.alves@ufv.br \\ ${ }^{2}$ Eng. Florestal, Dr., Depto. Engenharia Florestal, UFV, Viçosa, MG, Brasil - jacovine@ufv.br \\ ${ }^{3}$ Bacharela em Gestão de Cooperativas, UFV, Viçosa, MG, Brasil - fabriciaufv@ hotmail.com \\ ${ }^{4}$ Administradora, M.Sc., UFV, Viçosa, MG, Brasil - vavpires2005@ yahoo.com.br \\ ${ }^{5}$ Administradora, Faculdade Ubaense Gov. Ozanam Coelho, FAGOC, Ubá, MG, Brasil - deia2023@ hotmail.com \\ Recebido para publicação: 13/08/2007 - Aceito para publicação: 18/11/2008
}

\begin{abstract}
Resumo
O presente trabalho teve como objetivo geral avaliar a percepção sobre o uso de madeira reflorestada pelos consumidores finais do Polo Moveleiro de Ubá, em Minas Gerais. Para a obtenção dos dados desta pesquisa, optou-se pela aplicação de um questionário aos consumidores que visitaram a sétima edição da Feira de Móveis de Minas Gerais (FEMUR), realizada em maio de 2006. Verificou-se que $34 \%$ dos consumidores se preocupam com a procedência da madeira que está no móvel, sendo que esse percentual aumenta quando ele fica sabendo que a madeira provém de desmatamento ilegal da Amazônia, fazendo-o ser mais rigoroso na sua decisão de compra. Cerca de $78 \%$ dos consumidores demonstraram conhecer a utilização de madeira de reflorestamento nos móveis do polo, principalmente o pinus e o eucalipto, sendo que $64 \%$ estariam dispostos, também, a comprar esses móveis. Conclui-se que os consumidores do Polo Moveleiro de Ubá, em geral, apresentam uma preocupação com o tipo de madeira presente nos móveis que adquirem. Os consumidores estariam dispostos a adquirir um móvel feito de madeira reflorestada, como o eucalipto ou pinus, caso possuíssem essa opção no mercado, sendo uma oportunidade para minimizar a pressão sobre as florestas nativas.
\end{abstract}

Palavras-chave: Indústria moveleira; mercado moveleiro; comportamento do consumidor.

\begin{abstract}
Consumer perception of the use of reforested wood in furniture produced in the Ubá Furniture Cluster. This study aimed at evaluating the general perception on the use of reforested wood by final consumers of the Ubá Furniture Cluster, in Minas Gerais. Data for this study were obtained from a questionnaire to consumers who visited the Seventh Furniture Fair held in May 2006 in Minas Gerais (FEMUR). It was found that $34 \%$ of consumers worry about the origin of wood used in pieces of furniture, and this percentage increases when they learn that the wood comes from illegal deforestation of the Amazon, making them more scrupulous with their purchase decisions. Around $78 \%$ of consumers knew about the use of reforested wood in the furniture, mainly pine and eucalyptus, and $64 \%$ would also be willing to buy them. The results showed that consumers of Ubá Furniture Cluster, in general, are concerned with the type of wood used in the furniture. Consumers are willing to consume furniture made of reforested wood, such as eucalyptus or pine, if they have this choice in the market, which is an opportunity to alleviate the pressure on native forests.

Keywords: Furniture industry; furniture market; consumer behavior.
\end{abstract}

\section{INTRODUÇÃO}

O desmatamento, a maior consciência ambiental dos consumidores e as restrições ao comércio de madeiras nativas estimulou o surgimento de um novo padrão de produção e consumo de produtos de origem florestal. A oferta de madeiras nativas no mercado tem diminuído em razão de sua menor disponibilidade nas áreas atuais de produção, ocasionando o distanciamento entre as florestas ainda 
existentes e a zona de consumo. Esse fato tem estimulado o surgimento de alternativas, dentre as quais, o uso de madeira oriunda de reflorestamento, destacando-se o uso das espécies pinus e eucalipto.

Segundo Silva; Polledna (2002), o eucalipto é um gênero provindo da Austrália, formado por mais de 700 espécies. Trata-se de uma árvore com taxa de crescimento extremamente alta, o que a coloca em uma posição de insumo de fonte renovável de forte uso comercial. Além disso, conforme Aracruz (2006), essa madeira possui múltiplas finalidades. Da fibra se faz a celulose para produção de diversos tipos de papel, tecido sintético e cápsulas de remédios, e a madeira é utilizada na produção de móveis, acabamentos refinados de construção civil, pisos, postes e mastros para barcos.

Quanto ao pinus, existem em torno de 95 espécies largamente difundidas. Possui grande adaptação a climas e solos diversos, ocorrendo nas Américas, Ásia, Europa e África. No Brasil existem em torno de 30 mil km² de florestas plantadas de Pinus spp., podendo-se citar Pinus elliottii, Pinus taeda, Pinus caribea, Pinus hondurensis e mais algumas espécies de menor expressão. A procura do mercado interno é grande e a exportação está em fase de crescimento, com destaque para painéis colados, portas, componentes para a construção e móveis. Os compradores externos são os EUA, Canadá e Europa (STUMPP, 2008).

A indústria moveleira no Brasil tem sido marcada por um processo de utilização crescente de matéria-prima florestal proveniente de plantios florestais, seja madeira maciça ou mesmo painéis reconstituídos e chapas, como MDF, aglomerado, OSB e compensado.

Para Silva (2003a), a indústria de produtos à base de madeira tem se defrontado com desafios que estão provocando drásticas mudanças: i) crescente expansão dos mercados para a "madeira ambientalmente correta", exemplificada pela crescente força mercadológica dos "selos verdes" em todo o mundo; ii) globalização dos mercados consumidores, com a consequente necessidade de aumento na produtividade e o atendimento a padrões de qualidade cada vez mais exigentes.

Sobre o primeiro desafio, pode-se verificar que a indústria moveleira nacional tem buscado, mesmo que timidamente, a certificação florestal (selo verde), como forma de atender a mercados mais exigentes em termos ambientais. Além disso, os custos envolvidos na sua obtenção são considerados acessíveis a boa parte das empresas, sendo que a certificação florestal é fundamental para algumas empresas, em determinados mercados (JACOVINE et al., 2006a; JACOVINE et al., 2006b; ALVES et $a l .$, 2007). Sobre o segundo desafio, Silva (2003b) destacou que a necessidade de aumento da produtividade e atendimento a certos padrões de qualidade têm estimulado a exploração de madeira de plantios florestais, principalmente das espécies pinus e eucalipto.

Nesse contexto, o uso de madeiras oriundas desses plantios pela indústria moveleira, além de seu caráter indispensável, visto a série de restrições ao comércio de madeiras nativas, também possui um forte apelo ecológico e de responsabilidade social. Segundo Donaire (1999), as empresas têm passado por várias mudanças nas últimas décadas e, dentre elas, a necessária inclusão da responsabilidade de ajudar a sociedade a resolver alguns de seus problemas sociais, muitos dos quais as próprias organizações ajudaram a criar.

O consumidor, ao decidir por uma compra, é influenciado por uma série de características. De acordo com Kotler e Armstrong (1998), as características que influenciam os consumidores no momento das compras são de ordem cultural, social, pessoal e psicológica. Embora os profissionais de marketing geralmente não consigam controlar esses fatores, precisam levá-los em consideração ao traçar suas estratégias. Cada um dos quatro fatores mencionados anteriormente é composto por subfatores que afetam o poder de escolha do consumidor, entre os quais destacam-se a classe social, o status, a idade e o estágio do ciclo de vida, a ocupação, a situação econômica, o estilo de vida, a percepção, o aprendizado, as crenças e as atitudes.

Por meio de ações e do aprendizado, as pessoas formam suas crenças e atitudes, as quais, por sua vez, influenciam o comportamento de compra. Crença é um pensamento descritivo da pessoa sobre alguma coisa. Atitudes são avaliações, sentimentos e tendências relativamente consistentes quanto a um objeto ou ideia (KOTLER; ARMSTRONG, 1998).

Segundo Mowen; Minor (2003), percepção é o processo por meio do qual indivíduos são expostos à informação, prestam atenção nela e a compreendem. No estágio da exposição inicial, os consumidores recebem a informação por meio dos sentidos. No estágio de atenção, eles se concentram em um estímulo e para ele direcionam sua capacidade de processamento. No estágio de compreensão, eles organizam e interpretam a informação a fim de captar seu significado. 
Alguns estudos sobre percepção de consumo têm sido feitos em diferentes áreas. Saes e Spers (2006) verificaram se as estratégias de diferenciação dos produtores rurais de café, por meio da introdução de produtos que valorizem a origem ou o processo de produção, eram percebidas pelos consumidores brasileiros. Para isso, eles fizeram uma pesquisa com 300 consumidores de classe social alta, em cafeterias e supermercados do município de São Paulo. Os resultados demonstraram uma percepção de valor para os cafés que foram produzidos em processo que não empregam agrotóxicos. Ferraz (2001) avaliou o comportamento do consumidor frente à informação nutricional em rotulagem de produtos alimentícios, buscando fornecer subsídios para melhorar o processo de comunicação entre as indústrias de alimentos e o próprio consumidor. A pesquisa foi realizada com consumidores de supermercados da cidade de Belo Horizonte (MG), no ato da compra. Os resultados mostraram que o consumidor lê com mais frequência informações nutricionais associadas a riscos à saúde, como valor calórico, gordura e colesterol.

Dessa forma, estudar a percepção, crença e atitude do consumidor frente ao uso de madeira reflorestada em móveis torna-se importante. Sendo assim, o presente trabalho teve como objetivo geral avaliar a percepção sobre o uso de madeira reflorestada pelos consumidores do Polo Moveleiro de Ubá, em Minas Gerais.

Especificamente, procurou-se:

- conhecer o comportamento do consumidor do Polo de Ubá (MG) com relação à procedência da madeira do móvel que ele compra;

- analisar o comportamento do consumidor do Polo de Ubá (MG) com relação à compra ou não de um móvel sabendo que a madeira com que ele foi feito é oriunda de desmatamento ilegal na Amazônia;

- verificar se o consumidor tem conhecimento sobre o uso de madeira de eucalipto e pinus nos móveis fabricados;

- analisar a intenção de consumo em relação a móveis fabricados com madeira originada de reflorestamento, sobretudo pinus ou eucalipto.

\section{MATERIAL E MÉTODOS}

Nas pesquisas de mercado, utiliza-se a aplicação direta ou adaptada de métodos de pesquisa usados nas diferentes disciplinas que estudam o homem. A pesquisa aplicada ao comportamento do consumidor segue o procedimento científico, tanto quanto nas outras disciplinas, e os resultados obtidos são validados por pesquisadores internacionalmente reconhecidos. Dentre os métodos de pesquisa mencionados, destaca-se o levantamento, no qual o pesquisador elabora um questionário a ser aplicado às pessoas que representam a população de interesse (KARSAKLIAN, 2004). As perguntas do questionário devem conduzir facilmente as respostas, de forma a não insinuarem outras colocações, e podem ser fechadas ou abertas. Além disso, as questões devem estar relacionadas com um problema central e ser aplicadas por elementos selecionados e preparados (GIL, 1991; CERVO; BERVIAN, 2002).

Dessa forma, aplicou-se um questionário, com perguntas abertas e fechadas, aos consumidores que estiveram presentes na sétima edição da Feira de Móveis de Minas Gerais (FEMUR), realizada em 2006, na cidade de Ubá, sede do maior polo moveleiro do estado. A aplicação do questionário foi realizada por uma equipe composta por profissionais de Administração e de Gestão de Cooperativas, que receberam treinamento sobre o assunto pesquisado.

A FEMUR é uma das mais importantes feiras de móveis do país e é realizada a cada dois anos. A feira atrai expositores e visitantes de várias localidades, dentro e fora de Minas Gerais. Em 2006, a feira foi feita em duas etapas: cinco dias destinados a representantes, empresários, revendedores e fornecedores, entre outros, com entrada permitida mediante convite; e um dia aberto ao consumidor final, com acesso livre, e no qual foi realizada a presente pesquisa.

No dia aberto ao consumidor final, segundo estimativas da organização do evento, estiveram presentes cerca de 4.000 consumidores, vindos de diversas cidades da região. Foram aplicados 116 questionários, correspondendo, de forma estimada, a 2,9\% do total. Esse percentual encontra-se de acordo com o exigido pela diretriz para seleção do tamanho mínimo da amostra citada por Little (1997) e conforme demonstrado na tabela 1 . Dos 116 questionários, 60 (52\% do total) foram aplicados a homens e 56 (48\% do total) a mulheres. 
Tabela 1. Diretriz para seleção do tamanho da amostra.

Table 1. Guidelines for selection of sample size.

\begin{tabular}{lc}
\hline Tamanho da população & $\begin{array}{c}\text { Tamanho mínimo da amostra sugerido } \\
\text { medianamente rigoroso }\end{array}$ \\
\hline $2-10$ & $100 \%$ \\
$11-25$ & $40 \%$ \\
$26-50$ & $20 \%$ \\
$51-100$ & $10 \%$ \\
$101-250$ & $7 \%$ \\
$251-500$ & $5 \%$ \\
$501-1000$ & $3 \%$ \\
Acima de 1000 & $2 \%$ \\
\hline
\end{tabular}

Fonte: Little (1997).

Os dados referentes às respostas do questionário foram organizados e sistematizados por meio de tabulação, utilizando-se uma planilha eletrônica.

\section{RESULTADOS E DISCUSSÃO}

Os resultados são apresentados e discutidos conforme a sequência apresentada nos objetivos específicos mencionados anteriormente. Antes, porém, serão apresentadas algumas características do perfil dos consumidores estudados.

\section{Perfil dos consumidores estudados}

A maior parte dos consumidores que responderam a pesquisa concentra-se em duas faixas etárias: 20-29 anos e 30-39 anos (Figura 1). Essas duas faixas representam uma parcela muito importante da população economicamente ativa e, por isso mesmo, representam potenciais consumidores de móveis, visto que possuem renda para consumo. De acordo com Kotler e Armstrong (1998), ao longo da vida as pessoas mudam seus hábitos de compra de produtos e serviços. As preferências por comida, roupas, móveis e diversões são sempre relacionadas com a idade. A compra também é moldada pelo estágio do ciclo de vida familiar - estágios pelos quais a família passa à medida que seus membros amadurecem.

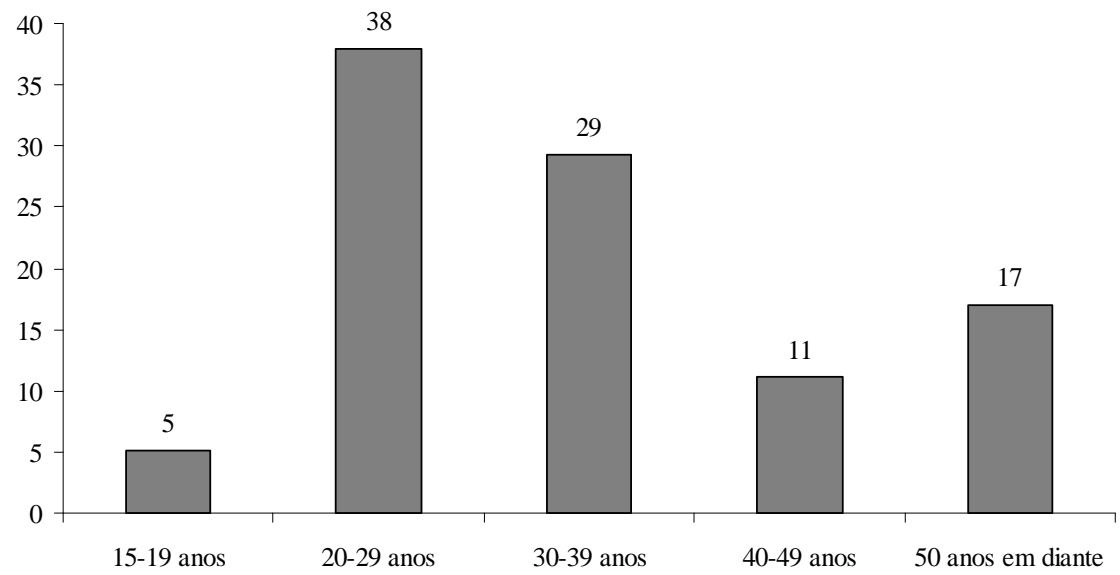

Figura 1. Faixa etária dos consumidores que responderam à pesquisa, em \%.

Figure 1. Age group of consumers who responded to the survey, in $\%$.

Com relação à escolaridade, verificou-se que a maioria dos consumidores possui formação escolar até o segundo grau completo (Figura 2), sendo $74 \%$ para homens e $68 \%$ para mulheres. Há uma grande heterogeneidade da formação escolar dos consumidores de móveis do polo moveleiro de Ubá. Possivelmente esse fato reflete no nível de exigência no momento de decidir pela compra e tende a contribuir para que o preço seja o fator principal na escolha. O nível de instrução da população da região 
também tem impacto no tipo de mão-de-obra empregado nas empresas. Segundo Crocco et al. (2001), o polo de Ubá segue uma tendência da indústria nacional de móveis, empregando pessoal não-qualificado e com baixo nível de escolaridade. Com relação ao pessoal de gerência, o segmento dominante é o de $2^{\circ}$ grau completo (Ensino Médio), ressaltando-se que apenas 15\% concluíram o curso superior.
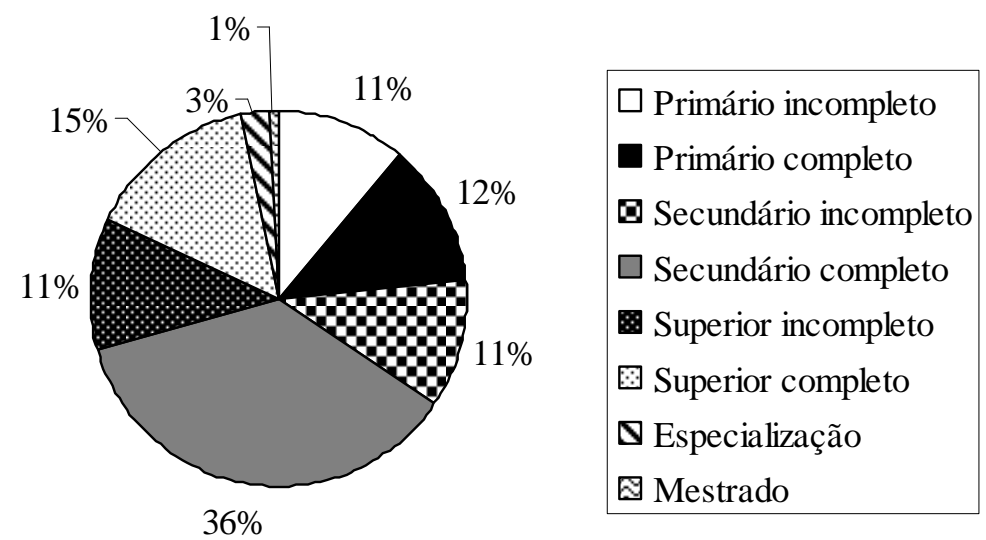

Figura 2. Grau de instrução dos consumidores que responderam à pesquisa.

Figure 2. Level of education of consumers who responded the survey.

Com relação à profissão exercida pelos consumidores que responderam à pesquisa, verificou-se uma grande heterogeneidade. As profissões mais citadas pelos homens foram: marceneiro, empresário, professor, operador de máquina, policial e representante comercial. Já entre as mulheres, a profissão mais citada foi a de dona de casa. Outras profissões relatadas pelas entrevistadas: costureira, auxiliar de escritório, jornalista, auxiliar de produção, estudante, vendedora e professora.

\section{Comportamento do consumidor quanto à procedência da madeira nos móveis}

Em torno de 34\% dos consumidores informou que se preocupa com a procedência da madeira que está no móvel (Figura 3). Alguns consumidores declararam que algumas vezes se preocupam, não deixando clara a frequência com que isso ocorre.

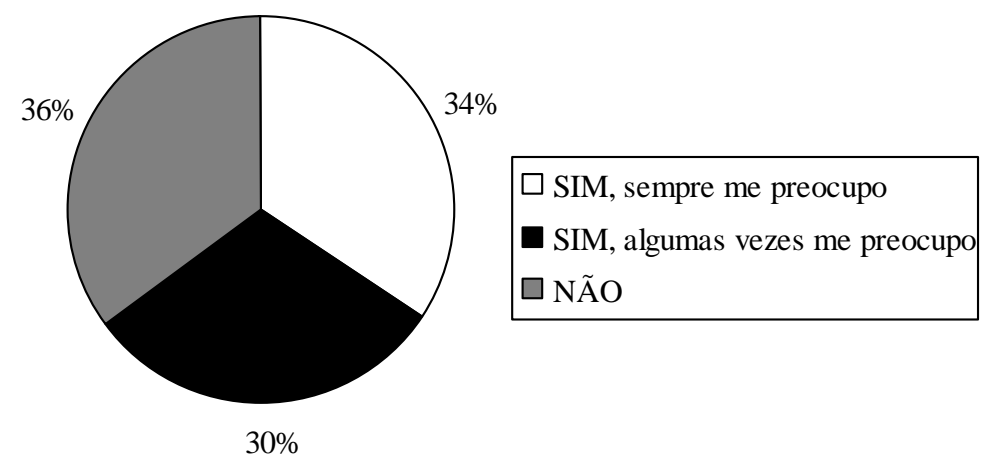

Figura 3. Preocupação dos consumidores com relação à procedência da madeira presente nos móveis.

Figure 3. Concern of consumers regarding the origin of the wood.

Verificou-se, no entanto, uma preocupação ligeiramente superior por parte das mulheres (39\%) em relação aos homens (30\%) (Figuras 4 e 5). As respostas dos homens, entretanto, estiveram bem dispersas nas três opções, enquanto que a das mulheres estavam tendendo para as duas opções "sim, sempre se preocupa" ou "não", demonstrando que suas respostas são mais concisas. Verificou-se, então, que elas evitaram a opção "sim, algumas vezes me preocupo", que poderia dar margem a dúvida quanto à veracidade de sua preocupação quanto à procedência da madeira, por não deixar clara a frequência com que ocorre tal preocupação. 


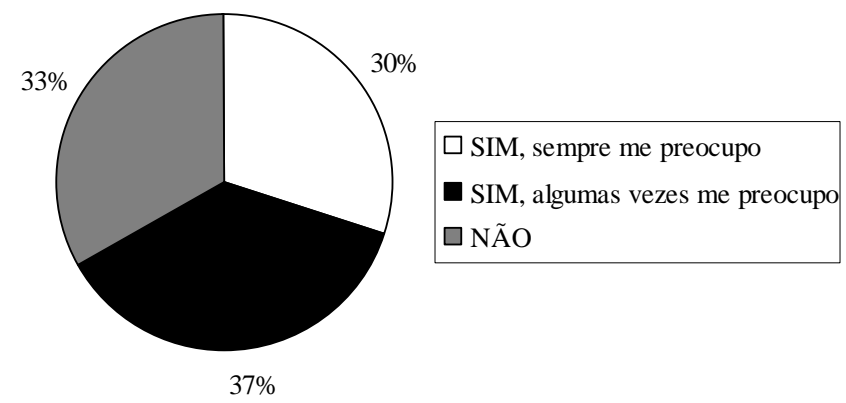

Figura 4. Preocupação dos homens com relação à procedência da madeira presente nos móveis. Figure 4. Concern of males regarding the origin of the wood.

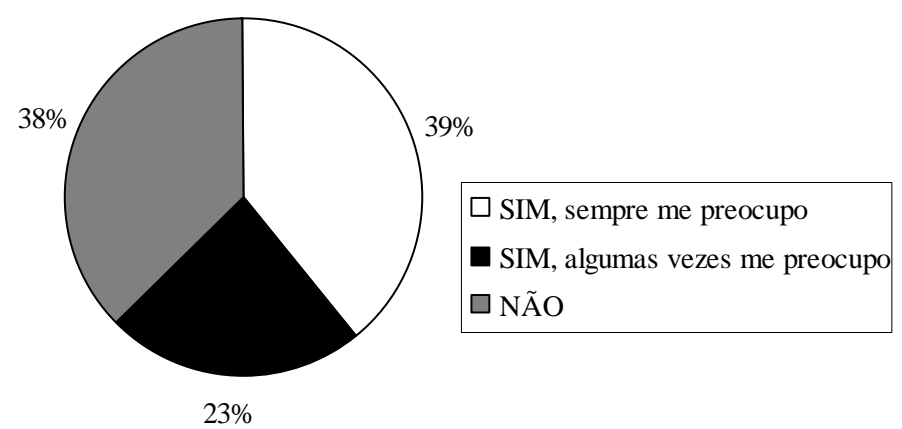

Figura 5. Preocupação das mulheres com relação à procedência da madeira presente nos móveis.

Figure 5. Concern of females regarding the origin of the wood.

Com relação ao comportamento de compra do consumidor caso soubesse que a madeira de um móvel que estivesse comprando fosse originada de desmatamento ilegal da Amazônia, verificou-se que cerca de $74 \%$ dos entrevistados não comprariam e o restante não teria objeção à compra desse móvel. Nesse quesito, as mulheres estariam mais dispostas a consumir esse móvel - com madeira ilegal - do que os homens ( $29 \%$ contra $23 \%$, respectivamente).

Várias razões para a compra de móvel oriundo de madeira de desmatamento ilegal da Amazônia foram relatadas pelos consumidores, sendo que a principal foi que a madeira já estaria cortada e não haveria mais o que fazer (Tabela 2).

Tabela 2. Razões para a compra de madeira oriunda de desmatamento ilegal da Amazônia.

Table 2. Reasons for purchasing wood from illegal deforestation of the Amazon.

\begin{tabular}{lcc}
\hline \multirow{2}{*}{ Descrição das razões de compra de madeira ilegal da Amazônia } & \multicolumn{2}{c}{ Respostas \% } \\
\cline { 2 - 3 } & Homens & Mulheres \\
\hline a) "o móvel já estaria pronto e não haveria nada mais para fazer”. & 11,66 & 3,57 \\
b) "a fiscalização cabe às autoridades competentes e não ao consumidor". & 1,67 & 1,78 \\
c) "se o consumidor gostar do móvel e do preço, ele vai comprar independente da & 1,67 & 3,57 \\
origem da madeira". & 1,67 & 1,78 \\
d) "quem deve evitar a compra desta madeira é a empresa moveleira”. & 1,67 & 3,57 \\
e) "existe uma acomodação do consumidor e a procedência da madeira não se & \\
constitui numa grande preocupação". &
\end{tabular}

Por outro lado, a maioria dos homens $(77 \%)$ e mulheres $(71 \%)$ relatou que não comprariam um móvel se soubessem que sua madeira provém de desmatamento ilegal da Amazônia. As principais razões para não se consumir um móvel com madeira dessa procedência estão descritas na tabela 3. 
Tabela 3. Razões para não se comprar madeira oriunda de desmatamento ilegal da Amazônia.

Table 3. Reasons for not buying wood from illegal deforestation of the Amazon.

\begin{tabular}{lcc}
\hline \multirow{2}{*}{ Descrição das razões para não se comprar madeira ilegal da Amazônia } & \multicolumn{2}{c}{ Respostas \% } \\
\cline { 2 - 3 } a) "consumir um móvel com este tipo de madeira significaria agir contra a lei”. & 15,00 & Mulheres \\
b) "este tipo de exploração da madeira agride a natureza e o meio ambiente". & 6,66 & 1,78 \\
c) "não contribuir para a continuidade deste processo de desmatamento". & 3,33 & 14,28 \\
d) "ajudar as empresas que trabalham de forma correta e penalizar o vendedor & 1,66 & 1,78 \\
desonesto". & 1,66 & 1,78 \\
e) "ter responsabilidade com o meio ambiente". & \\
\hline
\end{tabular}

Pelos resultados apresentados anteriormente na figura 3, pode-se verificar que $34 \%$ dos consumidores "sempre se preocupam" com a correta procedência da madeira. No entanto, quando o consumidor toma conhecimento de que a madeira provém de desmatamento ilegal da Amazônia, ele passa a se preocupar mais e se torna mais rigoroso na tomada de decisão para escolher o móvel, rejeitando-o em mais de $70 \%$ dos casos, sendo que suas razões foram descritas na tabela 3 .

\section{Comportamento do consumidor quanto ao uso de madeira de reflorestamento nos móveis}

Cerca de $78 \%$ dos consumidores pesquisados demonstrou conhecer a utilização de madeira de reflorestamento nos móveis do polo, principalmente o pinus e o eucalipto. O percentual se mantém o mesmo nos resultados envolvendo homens e mulheres.

Estariam dispostos a comprar um móvel feito com essa madeira $64 \%$ dos consumidores pesquisados. O percentual de homens que compraria um móvel feito dessas essências florestais foi significativamente maior do que o de mulheres (75\% a 53\%), demonstrando uma maior aceitabilidade dos primeiros a respeito das características favoráveis do pinus e do eucalipto na confecção de móveis.

No estudo realizado por Teixeira (2005), acerca da percepção do uso da madeira de eucalipto pelos fabricantes do Polo Moveleiro de Ubá, constatou-se que vários fatores influenciavam na sua utilização por parte das empresas, sendo principais o fato de a madeira ser oriunda de floresta plantada, possuir características uniformes, existir uma escassez de madeira nativa para compra, a madeira de eucalipto ter preço atrativo e ter havido aumento do preço da madeira nativa, sendo que apenas uma pequena parte das empresas do Polo de Ubá justificou o uso da madeira de eucalipto devido à demanda por parte do consumidor.

Visto que a maioria dos consumidores pesquisados neste trabalho (64\%) demonstrou disposição em comprar móveis feitos de eucalipto ou pinus, indicando uma tendência de consumo, as empresas que trabalham com eucalipto no polo poderiam relatar aos consumidores as vantagens da utilização dessa madeira renovável em substituição à madeira nativa, contribuindo para se evitar o desmatamento. Além da imagem "verde" passada pela empresa, ainda haveria a possibilidade de atrair os consumidores que possuem resistência a consumir móveis feitos por painéis reconstituídos e que preferem madeira maciça.

Para os $64 \%$ de consumidores pesquisados várias são as razões que os levariam a consumir um móvel feito de madeira de pinus ou eucalipto (Tabela 4).

Para os consumidores pesquisados que não comprariam um móvel feito de pinus ou eucalipto (36\%), existe uma série de razões, demonstradas na tabela 5.

Muitas dessas razões residem em falta de conhecimento e em mitos, não somente por parte dos consumidores, mas também das empresas existentes no Polo de Ubá, de que o eucalipto não oferece condições para o aproveitamento como madeira serrada, produção de lâminas e produtos acabados (TEIXEIRA, 2005). Contribui para esse cenário o fato de que muitas empresas fornecedoras da madeira não utilizam a tecnologia adequada, como clones apropriados, técnicas silviculturais, técnicas para corte, secagem e processamento, que contribuiriam para melhorar a qualidade das madeiras de eucalipto e pinus na fabricação dos móveis.

Silva (2003b) relatou que para se pensar na utilização de madeira para fins mais nobres, como a produção de móveis e o seu uso em decorações e construção civil, torna-se necessário aprimorar as características de ordem silvicultural e incorporá-las a vários outros programas de melhoramento genético e de manejo e condução da floresta, como o desbaste e a desrama, além de avaliar outros aspectos especiais da madeira, como a ausência de nós e outros defeitos superficiais, os níveis de tensões de crescimento da madeira juvenil, de estabilidade dimensional, resistência mecânica, trabalhabilidade, desenhos e coloração. 
Tabela 4. Razões para se consumir um móvel feito de madeira de pinus ou eucalipto.

Table 4. Reasons for buying a piece of furniture made of pine or eucalyptus wood.

\begin{tabular}{lcc}
\multicolumn{1}{c}{$\begin{array}{c}\text { Descrição das razões para se consumir um móvel feito de madeira de } \\
\text { pinus ou eucalipto }\end{array}$} & \multicolumn{2}{c}{ Respostas \% } \\
\cline { 2 - 3 } a) a madeira provém de reflorestamento e contribui para diminuir a pressão sobre as & Homens & Mulheres \\
florestas nativas. & 11,67 & 16,07 \\
b) consideram a madeira de boa qualidade. & 10,00 & 10,71 \\
c) acreditam que os móveis são bons, duráveis e que não apresentam problemas. & 8,33 & 1,78 \\
d) preço menor. & 3,33 & 5,35 \\
e) julgam possuir boa resistência. & 3,33 & 0,00 \\
f) acreditam que a madeira possui um controle ambiental maior. & 1,66 & 3,57 \\
g) consideram a madeira mais leve e mais fácil de se encontrar, em comparação com as & 1,66 & 0,00 \\
outras. & 1,66 & 0,00 \\
h) se baseiam na tradição do uso desta madeira em sofás e estofados. & 1,66 & 3,57 \\
i) consideram que o acabamento realizado nestas madeiras são satisfatórios. &
\end{tabular}

Tabela 5. Razões para não se consumir um móvel feito de madeira de pinus ou eucalipto.

Table 5. Reasons for not buying a piece of furniture made of pine or eucalyptus wood.

\begin{tabular}{lccc}
\multicolumn{1}{c}{$\begin{array}{c}\text { Descrição das razões para não se consumir um móvel feito de madeira de } \\
\text { pinus ou eucalipto }\end{array}$} & \multicolumn{2}{c}{ Respostas \% } \\
\cline { 2 - 4 } & Homens & Mulheres \\
\hline a) consideram que estas madeiras são de baixa qualidade. & 15,00 & 21,43 \\
b) acreditam que possuem pouca resistência. & 1,67 & 3,57 \\
c) consideram que seu uso adequado seria apenas em partes do móvel e não nele todo. & 1,67 & 0,00 \\
d) não julgam haver um acabamento nesta madeira que seja satisfatório. & 1,67 & 3,57 \\
e) estas madeiras não proporcionariam um bom "design" nos móveis. & 0,00 & 3,57 \\
f) consideram que são madeiras suscetíveis ao aparecimento de "carunchos". & 0,00 & 1,78 \\
\hline
\end{tabular}

O tratamento adequado da madeira é o grande segredo da sua versatilidade, comprovando que vários de seus problemas podem ser contornados com a utilização correta de equipamentos e procedimentos. Há a necessidade de esforços cada vez maiores no sentido de adequação de tecnologias de processamento e utilização das espécies já conhecidas (SILVA, 2003b).

Uma parcela dos consumidores do Polo de Ubá demonstrou preocupação ambiental com a procedência da madeira oriunda dos móveis que consome e uma propensão a adquiri-los quando feitos de madeiras alternativas às advindas de florestas nativas, como o pinus e o eucalipto. Dessa forma, as empresas devem obter maiores informações técnicas a respeito do seu uso na fabricação dos móveis e, sempre que possível, informar ao consumidor as vantagens advindas da compra de móveis feitos com madeira de plantios florestais.

\section{CONCLUSÕES}

Pelos resultados apresentados neste trabalho, pode-se concluir que:

- uma parcela dos consumidores do polo moveleiro de Ubá (MG) apresentou preocupação com relação à correta procedência da madeira presente nos móveis que consome;

- os consumidores do polo demonstraram uma propensão em não consumir um móvel se souberem que sua madeira provém de desmatamento ilegal da Amazônia;

- os consumidores do polo demonstram conhecimento a respeito da utilização de madeira de reflorestamento, como pinus e eucalipto, na fabricação dos móveis;

- existe uma demanda no consumo de móveis feitos a partir de pinus ou eucalipto no polo moveleiro de Ubá.

\section{AGRADECIMENTOS}

À Fundação de Amparo à Pesquisa do Estado de Minas Gerais (FAPEMIG), pelo financiamento da pesquisa e ao Departamento de Engenharia Florestal da Universidade Federal de Viçosa (UFV), pelo apoio à pesquisa. 


\section{REFERÊNCIAS}

ALVES, R. R.; JACOVINE, L. A. G.; SILVA, M. L. da; VALVERDE, S. R. Certificação florestal na visão gerencial e estratégica do Pólo Moveleiro de Ubá, MG. Cerne, Lavras, v. 13, n. 1, p. 117-122, 2007.

ARACRUZ S. A. Apresenta informações gerais da empresa. Disponível em: 〈http://aracruz.com.br/>. Acesso em: 25/06/2006.

CERVO, A. L.; BERVIAN, P. A. Metodologia científica. 5. ed. São Paulo: Prentice Hall, 2002. 242 p.

CROCCO, M.; SANTOS, F.; SIMÕES, R.; HORÁCIO, F. Pesquisa - Industrialização descentralizada: sistemas industriais locais. O arranjo produtivo moveleiro de Ubá, MG. Belo Horizonte: CEDEPLAR, 2001. 85 p.

DONAIRE, D. Gestão ambiental na empresa. São Paulo: Atlas, 1999. 169 p.

FERRAZ, R. G. Comportamento do consumidor frente à informação nutricional em rotulagem de produtos alimentícios - um estudo no varejo de Belo Horizonte/MG. 107 p. Dissertação (Mestrado em Ciência e Tecnologia de Alimentos) - Universidade Federal de Viçosa, Viçosa, MG, 2001.

GIL, A. C. Como elaborar projetos de pesquisa. São Paulo: Atlas, 1991. 176 p.

JACOVINE, L. A. G.; ALVES, R. R.; VALVERDE, S. R.; SILVA, M. L. da. Certificação florestal na visão gerencial e estratégica da indústria moveleira nacional. Semina. Ciências Agrárias, Londrina, v. 27, n. 3, p. 363-374, 2006a.

JACOVINE, L. A. G.; ALVES, R. R.; VALVERDE, S. R.; SILVA, M. L.; NARDELLI, A. M. B.; SOUZA, A. P. de. Processo de implementação da certificação florestal nas empresas moveleiras nacionais. Revista Árvore, Viçosa, MG, v. 30, n. 6, p. 961-968, $2006 \mathrm{~b}$.

KARSAKLIAN, E. Comportamento do consumidor. São Paulo: Atlas, 2004. 303 p.

KOTLER, P.; ARMSTRONG, G. Princípios de marketing. Rio de Janeiro: Prentice-Hall do Brasil, 1998. $527 \mathrm{p}$.

LITTLE, A. D. Auditoria de meio ambiente, saúde ocupacional e segurança industrial: fundamentos, habilidades e técnicas. São Paulo: Arthur D. Little, 1997. 270 p. (Apostila).

MOWEN, J. C.; MINOR, M. S. Comportamento do consumidor. São Paulo: Pearson Prentice Hall, 2003.

SAES, M. S. M.; SPERS, E. E. Percecpção do consumidor sobre os atributos de diferenciação no segmento rural: café no mercado interno. Organizações Rurais \& Agroindustriais: revista de administração da UFLA, Lavras, v. 8, n. 3, p. 354-367, 2006.

SILVA, J. C. Sinal verde para móveis de eucalipto? Revista da Madeira, Curitiba-PR, ano 13, n. 75, ago. 2003a.

SILVA, J. C. Por que usar eucalipto? Revista da Madeira, Curitiba-PR, ano 13, n. 75, ago. 2003 b.

SILVA, M. N. M.; POLLEDNA, S. R. C. O uso do eucalipto pelo setor moveleiro. In: CONGRESSO LATINO AMERICANO DAS ESCOLAS DE ADMINISTRAÇÃO, 37., 2002, Porto Alegre. Anais... Porto Alegre: [s.n.], 2002.

STUMPP, E. O futuro das madeiras de reflorestamento. Revista da Madeira, Curitiba-PR, ano 19, n. 112, p. 82-89, abr. 2008.

TEIXEIRA, T. O. B. A percepção sobre o uso da madeira de eucalipto pelos fabricantes do pólo moveleiro de Ubá, MG. 59 p. Dissertação (Mestrado em Ciência Florestal) - Universidade Federal de Viçosa, Viçosa, MG, 2005. 